\title{
Pertumbuhan Bibit Bud Chip tebu (Sacharum officinarum L.) Pada Beberapa Dosis Pupuk Kandang Kotoran Sapi
}

\author{
${ }^{1}$ Nasamsir dan ${ }^{2}$ Deffi Huffia \\ ${ }^{1}$ Program Studi Agroteknologi Fakultas Pertanian Universitas Batanghari \\ ${ }^{2}$ Alumni Program Studi Agroteknologi, Fakultas Pertanian, Universitas Batanghari \\ JL. Slamet Riyadi, Broni, Jambi, 36122. Telp. +6074160103 \\ ${ }^{1}$ e-mail koresponden : nasamsirsamsir@yahoo.co.id
}

\begin{abstract}
The development of sugarcane plantations, both by the people and the private sector, requires the availability of good and productive seeds, one of the supporting factors is the use of cow manure in the nursery media. The research conducted in the experimental garden of BPTP Jambi from January to March 2020. This research aims to provide facts about the use of cow manure on the growth of sugarcane seedlings from bud chips in the nursery. This study uses a non factorial completely randomized design $(C R D)$. The treatment that was tried was the dose of manure, including; $d 0=$ without manure, $d 1=130 \mathrm{~g}$ per polybag, $d 2=140 \mathrm{~g}$ per polybag, $d 3=150 \mathrm{~g}$ per polybag, $d 4=160 \mathrm{~g}$ per polybag and $d 5=170 \mathrm{~g}$ per polybag.The observed variables are; number of tillers, plant height $(\mathrm{cm})$, leaf length $(\mathrm{cm})$, stem diameter $(\mathrm{mm})$, root length $(\mathrm{cm})$, number of roots (strands), and soil pH, To answer the proposed hypothesis, the data obtained in the field were analyzed statistically using variance analysis, whereas to see differences between treatments using the DNMRT test at $\alpha 5 \%$ level. The results showed that the dose of cow manure did not significantly affect the number of tillers, plant height, leaf length, stem diameter, root length, and number of roots of sugarcane seedlings from bud chip but had a significant effect on soil pH
\end{abstract}

Keywords: bud chip, cow manure, sugarcane

\begin{abstract}
Abstrak. Pengembangan perkebunan tanaman tebu, baik oleh rakyat maupun swasta membutuhkan ketersediaan bibit yang baik dan produktif, salah satu faktor yang mendukung adalah penggunaan pupuk kandang kotoran sapi pada media pembibitan. .Penelitian dilakukan di Kebun Percobaan Balai Pengkajian Teknologi Pertanian (BPTP) Sungai TigaJambi.Penelitian ini dilaksanakan pada bulan Januari sampai Maret 2020. Penelitian ini bertujuan untuk memberikan fakta tentang pemanfaatan pupuk kandang kotoran sapi terhadap pertumbuhan bibit tebu asal bud chipdi pembibitan. Penelitian menggunakan rancangan lingkungan rancangan acak lengkap (RAL) non-faktorial. Perlakuan yang dicoba adalah dosis pupuk kandang, meliputi $; \mathrm{d}_{0}=$ Tanpa pupuk kandang, $\mathrm{d}_{1}=130 \mathrm{~g}$ per polibag, $\mathrm{d}_{2}=140 \mathrm{~g}$ per polibag, $\mathrm{d}_{3}=150 \mathrm{~g}$ per polibag, $\mathrm{d}_{4}=160 \mathrm{~g}$ per polibag dan $\mathrm{d}_{5}=170$ g per polibag. Peubah yang diamati yaitu; jumlah anakan, tinggi tanaman $(\mathrm{cm})$, panjang daun $(\mathrm{cm})$, diameter batang $(\mathrm{mm})$, panjang akar $(\mathrm{cm})$, jumlah akar (helai), dan $\mathrm{pH}$ tanah. Untuk menjawab hipotesis yang diajukan, data yang diperoleh di lapangan dilakukan analisis statistika menggunakan sidik ragam, sedangkan untuk melihat perbedaan antar perlakuan dilakukan uji lanjutan menggunakan uji DNMRT pada taraf $\alpha 5 \%$. Hasil penelitian menunjukkan dosis pupuk kandang kotoran sapi berpengaruh tidak nyata terhadap jumlah anakan, tinggi tanaman, panjang daun, diameter batang, panjang akar, dan jumlah akar bibit tebu asal bud chip akan tetapi berpengaruh nyata terhadap $\mathrm{pH}$ tanah.
\end{abstract}

Kata kunci : bud chip, pupuk kandang sapi, tanaman tebu

\section{PENDAHULUAN}

Di Indonesia tanaman tebu (Saccharum officinarum L.) mulai dikenal sejak kolonialisme Belanda dan semakin banyak dikembangkan oleh perusahaan BUMN maupun swasta, yang berada di pulau Jawa dan Sumatera. Tebu merupakan bahan baku pembuatan gula karena dari pangkal batang hingga ujungnya mengandung nira yang dapat diolah menjadi gula dengan kadar gula bervariasi, bergantung varietas, umur, dan cara pengolahannya (PTPN $X, 2015)$.

Bud chip merupakan benih tebu dalam bentuk mata tebu yang diambil dari batang tebu dengan mengikutsertakan sebagian dari primordial akar yang diambil dengan memotong sebagian ruas batang tebu (Purwati dan Parnidi, 2016). Benih tebu bud chip memiliki keunggulan, setelah dipindahtanam ke lapangan mampu membentuk 10-20 anakan. Anakan benih ini akan tumbuh sempurna sampai panen 8-10 batang per rumpun, sedangkan benih bagal hanya akan membentuk 1-4 anakan. Pembentukan anakan dari benih bud chip akan serempak pada umur 1-3 bulan (Balitbangtan, 2015). Penggunaan bahan tanam tebu dengan metode bud chip merupakan penerapan teknologi budidaya tebu untuk mencapai program swasembada gula nasional ( Irianti, Indrawati, dan Kusumastuti, 2017

Tebu termasuk tanaman yang sangat membutuhkan pupuk untuk dapat menghasilkan tebu dan gula yang lebih baik.Untuk memecahkan masalah ini diperlukan pupuk yang dapat menunjang pertumbuhan tanaman tebu dan kandungan gula di dalamnya (Amir, Hawalid, dan Nurhuda, 2017).

Pemupukan merupakan salah satu upaya yang ditempuh dalam memaksimalkan hasil tanaman. Menurut Hartatik, Husnain, dan Widowati (2015), pemupukan dilakukan sebagai upaya untuk mencukupi kebutuhan unsur 
hara tanaman agar tujuan produksi dapat dicapai. Namun apabila penggunaan pupuk yang tidak bijaksana atau berlebihan dapat menimbulkan masalah bagi tanaman yang diusahakan, seperti keracunan, rentan terhadap hama dan penyakit, kualitas produksi rendah dan selain itu biaya produksi tinggi dan dapat menimbulkan pencemaran.

Pupuk organik bermanfaat untuk meningkatkan produksi pertanian baik kualitas maupun kuantitas, mengurangi pencemaran lingkungan dan meningkatkan kualitas lahan secara berkelanjutan. Penggunaan pupuk organik dalam jangka panjang dapat meningkatkan produktivitas lahan dan dapat mencegah degredasi lahan. Dengan pemberian pupuk organik dalam jangka panjang mampu meningkatkan kandungan humus di dalam tanah. Pupuk organik memiliki fungsi kimia penting seperti penyediaan unsur hara makro (nitrogen, fospor, kalium, magnesium dan sulfur) dan unsur hara mikro (seng, tembaga, kobal, mangan dan besi) meskipun dalam jumlah yang kecil. Pupuk organik ini juga berfungsi meningkatkan humus tanah, meningkatkan kapasitas tukar kation tanah, dan membentuk senyawa kompleks dengan ion logam yang meracuni tanaman seperti alumunium, besi, dan mangan (Gusta, Kusumastuti dan Parapasan, 2015).

Hasil penelitian Amir, Hawalid dan Nurhuda (2017), menyimpulkan bahwa pemberian pupuk kandang kotoran sapi menghasilkan jumlah daun terbanyak pada bibit tanaman tebu.

Sejalan dengan penelitian ini, Evanita, Widaryanto dan Heddy (2014), menyimpulkan bahwa kombinasi tumpang sari dengan dosis pupuk kandang sapi yang berbeda memberikan pengaruh nyata terhadap pertumbuhan dan hasil tanaman terong dan rumput gajah.

Penelitian lain yang dilakukan oleh Havizah dan Mukarramah (2017) menyimpulkan, aplikasi pupuk kandang kotoran sapi berpengaruh nyata pada jumlah cabang produktif, jumlah buah pertanaman, dan berat buah pertanaman cabai rawit di tanah rawa lebak.

Berdasarkan hasil-hasil penelitian di atas, dapat disimpulkan bahwa tanaman-tanaman uji menunjukkan respon pertumbuhan dan hasil yang baik terhadap aplikasi pupuk kandang sapi.

\section{METODE PENELITIAN}

Penelitian ini dilaksanakan di kebun Percobaan Balai Pengkajian Teknologi Pertanian (BPTP) Sungai Tiga Jambi selama 3 bulan, mulai dari bulan Januari sampai bulan Meret 2020.

Bahan yang digunakan antara lain bibit tebu asal bud chip varietas POJ 2878 Agribun Kerinci umur 1 bulan, pupuk kandang kotoran sapi, tanah ultisol, dan air. Alat yang digunakan adalah cangkul, timbangan, meteran, jangka sorong, alat tulis, kertas label, gembor, polybag ukuran 10 x15 cm, ember, kamera, parang, paranet, ayakan, pH meter, dan penggaris.

Penelitian ini dilaksanakan secara eksperimen menggunakan rancangan acak lengkap (RAL) yang terdiri dari 6 taraf perlakuan dengan 3 ulangan, pada setiap satuan percobaan terdapat 8 tanaman dan 3 tanaman dijadikan sampel, sehingga jumlah keseluruhan sebanyak 144 tanaman.

Perlakuan yang diberikan adalah pupuk kandang kotoran sapi yang terdiri dari 6 taraf, sebagai berikut ;

$\mathrm{d} 0=$ Tanpa pemberian pupuk kandang kotoran sapi (800 $\mathrm{g}$ tanah).

$\mathrm{d} 1=$ pupuk kandang kotoran sapi $130 \mathrm{~g}$ dengan $670 \mathrm{~g}$ tanah.

$\mathrm{d} 2=$ pupuk kandang kotoran sapi $140 \mathrm{~g}$ dengan $660 \mathrm{~g}$ tanah.

$\mathrm{d} 3=$ pupuk kandang kotoran sapi $150 \mathrm{~g}$ dengan $650 \mathrm{~g}$ tanah.

$\mathrm{d} 4=$ pupuk kandang kotoran sapi $160 \mathrm{~g}$ dengan $640 \mathrm{~g}$ tanah.

$\mathrm{d} 5=$ pupuk kandang kotoran sapi $170 \mathrm{~g}$ dengan $630 \mathrm{~g}$ tanah.

Bibit tebu yang digunakan dalam penelitian ini adalah bibit tebu asal bud chip umur 1 bulan dengan tinggi $10 \mathrm{~cm}$, bibit yang dipilih yaitu bibit yang subur, sehat, lurus dan terbebas dari hama dan penyakit.

Tempat penelitian bebas dari gulma, kemudian diratakan untuk tempat menyusun polibag sesuai dengan ukuran petakan yang telah ditetapkan. Tempat penelitian diberi naungan dari paranet $25 \%$ dengan tinggi 1,5 meter, areal 3 x 4 meter dinaungi seluruhnya agar terhindar dari cahaya matahari langsung.

Media tanam yang digunakan adalah campuran tanah ultisol dengan pupuk kandang kotoran sapi dengan dosis sesuai perlakuan.Tanah dibersihkan dari sampah, rumput-rumput dan kotoran lainnya. Pupuk kandang kotoran sapi dijemur selama 14 hari, lalu diayak agar memiliki tekstur yang halus.

Bibit tanaman tebu yang berusia 1 bulan dengan tinggi $10 \mathrm{~cm}$ dipindahtanam ke dalam polibag $10 \times 15 \mathrm{~cm}$ dengan komposisi media sesuai percobaan yang telah ditentukan. Media tanam pada polibag kecil diusahakan tidak pecah pada saat pemindahan ke dalam polibag besar.

Perlakuan diberikan dengan cara mencampurkan pupuk kandang kotoran sapi dengan tanah ultisol sesuai dosis perlakuaan secara merata. Setelah pencampuran dengan pupuk kandang, media tanam diinkubasi selama 14 hari sebelum penanaman. Pemeliharaan yang dilakukan meliputi penyiraman, pengendalian gulma secara manual, serta pengendalian hama dan penyakit. 
Nasamsir dan Deffi Huffia. Pertumbuhan Bibit Bud Chiptebu (Sacharum officinarum L.) Pada Beberapa Dosis Pupuk Kandang Kotoran Sapi

Parameter yang diamati meliputi ;

1. Jumlah anakan yang muncul dari tanaman induk. Pengamatan dilakukan diakhir penelitian.

2. Tinggi tanaman, diukur mulai dari pangkal batang sampai dengan ujung daun tertinggi menggunakan penggaris. Pengamatan dilakukan diakhir penelitian.

3. Panjang daun, diukur menggunakan penggaris, dimulai dari pangkal lembaran daun hingga ujung daun pada daun terpanjang. Pengamatan dilakukan diakhir penelitian.

4. Diameter batang, diukur pada ketinggian batang $10 \mathrm{~cm}$ dari permukaan tanah menggunakan jangka sorong. Pengamatan dilakukan diakhir penelitian.

5. Panjang akar, diukur mulai dari pangkal akar hingga ujung akar, menggunakan penggaris. Pengamatan dilakukan diakhir penelitian

6. Jumlah akar, yaitu akar yang tumbuh dari pangkal batang, dilakukan diakhir penelitian

7. Pengukuran $\mathrm{pH}$ tanah menggunakan $\mathrm{pH}$ meter, dilakukan pada media tanam tanaman sampel setiap dosis perlakuan. Pengukuran dilakukan pada akhir penelitian.

Data hasil penelitian dianalisis statistika menggunakan analisis ragam. Bila analisis ragam menunjukkan pengaruh nyata, maka dilanjutkan dengan uji DNMRT taraf $\alpha 5 \%$.

\section{Jumlah Anakan}

\section{HASIL DAN PEMBAHASAN}

Berdasarkan data hasil pengamatan dan analisis ragam, pemberian pupuk kandang kotoran sapi dengan beberapa dosis memberikan pengaruh tidak nyata terhadap jumlah anakan tanaman tebu. Hasil uji lanjut DNMRT taraf $\alpha 5 \%$ untuk setiap perlakuan dapat dilihat pada Tabel 1 .

Tabel 1. Rata-rata Jumlah Anakan Tanaman Tebu pada Beberapa Dosis Pupuk Kandang Kotoran Sapi.

Pupuk Kandang Kotoran Sapi (g per media tanam)

$\begin{array}{cc}\text { d2 (140 gram) } & 0,11 \mathrm{a} \\ \text { d1 (130 gram) } & 0,11 \mathrm{a} \\ \text { d5 (170 gram) } & 0,00 \mathrm{a} \\ \text { d4 (160 gram) } & 0,00 \mathrm{a} \\ \text { d3 (150 gram) } & 0,00 \mathrm{a} \\ \text { d0 (0) } & 0,00 \mathrm{a}\end{array}$

Keterangan: angka-angka yang diikuti oleh huruf kecil yang sama berbeda tidak nyata pada taraf $\alpha$ 5\% uji DNMRT.

Dari Tabel 1 dapat dilihat bahwa perlakuan d2, dosis $140 \mathrm{~g}$ per media tanam memberikan hasil tertinggi terhadap jumlah anakan $(0,11$ batang), namun hasil ini berbeda tidak nyata bila dibandingkan dengan perlakuan d1, d5, d4, d3, dan d0.

\section{Tinggi Tanaman}

Berdasarkan data hasil pengamatan dan analisis ragam, pemberian pupuk kandang kotoran sapi dengan beberapa dosis memberikan pengaruh tidak nyata terhadap pertumbuhan tinggi tanaman tebu. Hasil uji lanjut DNMRT taraf $\alpha 5 \%$ untuk setiap perlakuan dapat dilihat pada Tabel 2

Tabel 2. Rata-rata Tinggi Tanaman Tebu Pada Beberapa Dosis Pupuk Kandang Kotoran Sapi.

\begin{tabular}{cc}
\hline Pupuk Kandang Kotoran Sapi (g per media tanam) & Tinggi Tanaman $(\mathrm{cm})$ \\
\hline d5 (170 gram) & $79,44 \mathrm{a}$ \\
d3 (150 gram) & $76,66 \mathrm{a}$ \\
d0 $(0)$ & $76,44 \mathrm{a}$ \\
d2 $(140$ gram $)$ & $75,55 \mathrm{a}$ \\
d4 (160 gram) & $75,11 \mathrm{a}$ \\
d1 (130 gram) & $73,88 \mathrm{a}$ \\
\hline
\end{tabular}

Keterangan: angka-angka yang diikuti oleh huruf kecil yang sama berbeda tidak nyata pada taraf $\alpha$ 5\% uji DNMRT.

Tabel 2 menggambarkan bahwa perlakuan d5, dosis $170 \mathrm{~g}$ per media tanam memberikan hasil tertinggi terhadap tinggi tanaman $(79,44 \mathrm{~cm})$, namun hasil ini berbeda tidak nyata bila dibandingkan dengan perlakuan $\mathrm{d} 3, \mathrm{~d} 0$, d2, d4 dan d1. Terdapat peningkatan tinggi tanaman antara perlakuan d5 dengan d0 sebesar 3,92\%. 
Nasamsir dan Deffi Huffia. Pertumbuhan Bibit Bud Chiptebu (Sacharum officinarum L.) Pada Beberapa Dosis Pupuk Kandang Kotoran Sapi

\section{Panjang Daun}

Berdasarkan data hasil pengamatan dan analisis ragam, pemberian pupuk kandang kotoran sapi dengan beberapa dosis memberikan pengaruh tidak nyata terhadap pertumbuhan panjang daun. Hasil uji lanjut DNMRT taraf $\alpha 5 \%$ untuk setiap perlakuan dapat dilihat pada Tabel 3 .

Tabel 3. Rata-rata Panjang Daun pada Beberapa Dosis Pupuk Kandang Kotoran Sapi.

\begin{tabular}{cc}
\hline Pupuk Kandang Kotoran Sapi (g per media tanam) & Panjang Daun $(\mathrm{cm})$ \\
\hline d5 (170 gram) & $39,77 \mathrm{a}$ \\
d4 (160 gram) & $39,77 \mathrm{a}$ \\
d0 (0) & $39,77 \mathrm{a}$ \\
d3 (150 gram) & $39,55 \mathrm{a}$ \\
d1 (130 gram) & $39,11 \mathrm{a}$ \\
d2 (140 gram) & $37,77 \mathrm{a}$ \\
\hline
\end{tabular}

Keterangan: angka-angka yang diikuti oleh huruf kecil yang sama berbeda tidak nyata pada taraf $\alpha$ 5\% uji DNMRT.

Dari Tabel 3 dapat dilihat bahwa perlakuan d5, dosis $170 \mathrm{~g}$ per media tanam memberikan hasil yang tertinggi terhadap panjang daun $(39,77 \mathrm{~cm})$, namun hasil ini berbeda tidak nyata bila dibandingkan dengan perlakuan $\mathrm{d} 4, \mathrm{~d} 0, \mathrm{~d} 3, \mathrm{~d} 1 \mathrm{dan} \mathrm{d} 2$. Tidak terdapat peningkatan panjang daun antara perlakuan d5 dengan d0, namun ada peningkatan panjang daun bila dibanding dengan perlakuan d2 sebesar 5,29\%.

\section{Diameter Batang}

Berdasarkan data hasil pengamatan dan analisis ragam, pemberian pupuk kandang kotoran sapi dengan beberapa dosis memberikan pengaruh tidak nyata terhadap diameter batang tanaman tebu. Hasil uji lanjut DNMRT taraf $\alpha 5 \%$ untuk setiap perlakuan dapat dilihat pada Tabel 4 .

Tabel 4. Rata-rata Diameter Batang Terbesar Tanaman Tebu pada Beberapa Dosis Pupuk Kandang Kotoran Sapi.

\begin{tabular}{cc}
\hline Pupuk Kandang Kotoran Sapi (g per media tanam) & Diameter Batang $(\mathrm{cm})$ \\
\hline d5 (170 gram) & $0,85 \mathrm{a}$ \\
d4 (160 gram) & $0,85 \mathrm{a}$ \\
d0 (0) & $0,84 \mathrm{a}$ \\
d2 (140 gram) & $0,83 \mathrm{a}$ \\
d1 (130 gram) & $0,82 \mathrm{a}$ \\
d3 (150 gram) & $0,81 \mathrm{a}$ \\
\hline
\end{tabular}

Keterangan: angka-angka yang diikuti oleh huruf kecil yang sama berbeda tidak nyata pada taraf $\alpha$ 5\% uji DNMRT.

Dari Tabel 4 terlihat bahwa perlakuan d5, dosis 170 g per media tanam memberikan hasil yang tertinggi terhadap diameter batang $(0,85 \mathrm{~cm})$, namun hasil ini berbeda tidak nyata bila dibandingkan dengan perlakuan $\mathrm{d} 4, \mathrm{~d} 0$, d2, d1 dan d3. Terdapat peningkatan diameter batang antara d5 dengan d0 sebesar 1,19\%.

\section{Panjang Akar}

Berdasarkan data hasil pengamatan dan analisis ragam, pemberian pupuk kandang kotoran sapi memberikan pengaruh tidak nyata terhadap panjang akar tanaman tebu. Hasil Uji DNMRT taraf $\alpha 5 \%$ untuk setiap perlakuan dapat dilihat pada Tabel 5

Tabel 5. Rata-rata Panjang Akar Tanaman Tebu pada Beberapa Dosis Pupuk Kandang Kotoran Sapi.

\begin{tabular}{cc}
\hline Pupuk Kandang Kotoran Sapi (g per media tanam) & Panjang Akar $(\mathrm{cm})$ \\
\hline d5 (170 gram) & $27,66 \mathrm{a}$ \\
d4(160 gram) & $25,27 \mathrm{a}$ \\
d0 (0) & $25,22 \mathrm{a}$ \\
d3 (150 gram) & $25,10 \mathrm{a}$ \\
d2 (140 gram) & $24,21 \mathrm{~b}$ \\
d1 (130 gram) & $23,82 \mathrm{~b}$ \\
\hline
\end{tabular}

Keterangan: angka-angka yang diikuti dengan huruf kecil yangsama berbeda tidak nyata pada taraf a 5\% uji DNMRT. 
Dari Tabel 5 terlihat bahwa perlakuan d5, dosis $170 \mathrm{~g}$ per media tanam memberikan hasil tertinggi terhadap panjang akar $(27,66 \mathrm{~cm})$, namun hasil ini berbeda tidak nyata bila dibandingkan dengan perlakuan $\mathrm{d} 4, \mathrm{~d} 0 \mathrm{dan} \mathrm{d} 3$, tetapi berbeda nyata dengan $\mathrm{d} 2$ dan $\mathrm{d} 1$. Demikian juga dengan perlakuan $\mathrm{d} 4$, d0, dan $\mathrm{d} 3$ berbeda tidak nyata satu sama lainnya, tetapi berbeda nyata dengan $\mathrm{d} 2$ dan $\mathrm{d} 1$. Perlakuan $\mathrm{d} 2$ berbeda tidak nyata dengan $\mathrm{d} 1$. Terdapat peningkatan panjang akar antara perlakuan d5 dengan d0 sebesar 9,67\%.

\section{Jumlah Akar}

Berdasarkan data hasil pengamatan dan analisis ragam, pemberian pupuk kandang kotoran sapi memberikan pengaruh tidak nyata terhadap jumlah akar tanaman tebu. Hasil uji lanjut DNMRT taraf $\alpha 5 \%$ untuk setiap perlakuan dapat dilihat pada Tabel 6

Tabel 6. Rata-rata Jumlah Akar Tanaman Tebu pada Beberapa Dosis Pupuk Kandang Kotoran Sapi.

\begin{tabular}{cc}
\hline Pupuk Kandang Kotoran Sapi (g per media tanam) & Jumlah Akar (helai) \\
\hline d5 (170 gram) & $6,99 \mathrm{a}$ \\
d3 (150 gram) & $6,77 \mathrm{a}$ \\
d1 (130 gram) & $6,33 \mathrm{a}$ \\
d2 (140 gram) & $6,10 \mathrm{a}$ \\
d4 (160 gram) & $5,88 \mathrm{a}$ \\
d0 (0) & $5,77 \mathrm{~b}$ \\
\hline
\end{tabular}

Keterangan: angka-angka yang diikuti oleh huruf kecil yang sama berbeda tidak nyata pada taraf $\alpha$ 5\% uji DNMRT.

Dari Tabel 6 terlihat bahwa perlakuan d5, dosis 170 g per media tanam memberikan hasil yang tertinggi terhadap jumlah akar (6,99 helai), namun hasil ini berbeda tidak nyata bila dibandingkan dengan perlakuan $\mathrm{d} 3, \mathrm{~d} 1$, d2 dan d4 tetapi berbeda nyata dengan d0. Demikian juga dengan perlakuan d3, d1, d2, dan d4 berbeda tidak nyata satu sama lainnya, tetapi berbeda nyata dengan $\mathrm{d} 0$. Terdapat peningkatan jumlah akar antara perlakuan d5 dengan d0 sebesar $21,14 \%$.

\section{Reaksi Tanah (pH)}

Berdasarkan data hasil pengamatan dan analisis ragam, pemberian pupuk kandang sapi dengan beberapa dosis memberikan pengaruh nyata terhadap $\mathrm{pH}$ tanah. Hasil uji lanjut DNMRT taraf $\alpha 5 \%$ untuk setiap perlakuan dapat dilihat pada Tabel 7.

Tabel 7. pH Tanah dari Beberapa Dosis Pupuk Kandang Kotoran Sapi.

\begin{tabular}{cc}
\hline Pupuk kandang kotoran sapi (g per media tanam) & $\mathrm{pH}$ tanah \\
\hline d3 (150 gram) & $7,30 \mathrm{a}$ \\
d1 (130 gram) & $6,73 \mathrm{a}$ \\
d4 (160 gram) & $6,63 \mathrm{a}$ \\
d2 (149 gram) & $6,60 \mathrm{a}$ \\
d5 (170 gram) & $6,56 \mathrm{a}$ \\
d0 (0) & $4,63 \mathrm{~b}$ \\
\hline
\end{tabular}

Keterangan: angka-angka yang diikuti oleh huruf kecil yang berbeda berpengaruh nyata pada taraf $\alpha$ 5\% uji DNMRT.

Dari Tabel 7 terlihat bahwa perlakuan d3, dosis 150 g per media tanam memberikan hasil yang tertinggi terhadap $\mathrm{pH}$ tanah $(7,3)$, namun hasil ini berbeda tidak nyata bila dibandingkan dengan perlakuan $\mathrm{d} 1, \mathrm{~d} 4, \mathrm{~d} 2 \mathrm{dan} \mathrm{d} 5$ tetapi berbeda nyata terhadap d0. Demikian juga perlakuan d1, d4, d2, dan $\mathrm{d} 5$ berbeda tidak nyata satu sama lainnya, tetapi berbeda nyata dengan d0. Terdapat perbedaan ph tanah antara perlakuan d3 dengan d0 sebesar 57,67\%.

Dari hasil analisis ragam menunjukkan bahwa pemberian pupuk kandang kotoran sapi dengan beberapa dosis memberikan pengaruh tidak nyata terhadap jumlah anakan, tinggi tanaman, panjang daun, diameter batang, panjang akar, dan jumlah akar bibit tebu asal bud chip. Hal ini diduga karena reaksi dari pupuk kandang kotoran sapi yang belum terdekomposisi sempurna sehingga lambat dalam proses pelepasan unsur hara untuk mendukung pertumbuhan vegetatif. Kondisi ini berakibat tidak adanya perbedaan ketersediaan unsur hara yang disumbangkan oleh pupuk kandang kotoran sapi dari dosis 130 g per media tanam sampai 170 g per media tanam sehingga belum mampu memberikan pengaruh yang signifikan. Pupuk kandang kotoran sapi lambat dalam proses pelepasan unsur 
hara ke dalam tanah, membutuhkan waktu yang cukup lama untuk dapat terdekomposisi dengan baik sehingga ketersediaan hara untuk tanaman terhambat.

Natsir, Salim dan Haldun (2017) menyatakan, pupuk organik membutuhkan waktu yang lama untuk dapat terdekomposisi secara sempurna, hal ini menyebabkan pupuk organik melepaskan unsur hara yang dikandungnya sedikit demi sedikit sehingga pupuk ini lambat reaksinya terhadap tanaman.

Sesuai dengan pendapat Hartatik, Husnain, dan Widowati (2015), ketersediaan unsur hara dari penggunaan pupuk kandang kotoran sapi lambat, hara yang berasal dari bahan organik diperlukan untuk kegiatan mikrobia tanah untuk diubah dari bentuk ikatan kompleks organik yang tidak dapat dimanfaatkan oleh tanaman menjadi senyawa organik dan anorganik sederhana yang dapat diserap oleh tanaman.

Pupuk kandang kotoran sapi mengandung mikroorganisme menguntungkan sehingga diharapkan dapat memperbaiki sifat fisik, kimia, dan biologi tanah. Nutrisi yang dikandung pupuk kandang tersebut dapat mendukung pertumbuhan tanaman. Namun, hasil penelitian menunjukkan jumlah anakan dan pertumbuhan bibit tebu tidak menunjukkan perbedaan nyata dengan kontrol, hal ini diduga karena masih terdapatnya cadangan makanan dalam bahan tanaman serta nutrisi yang terdapat dalam media tanam yang digunakan.

Pemberian pupuk kandang sapi dengan dosis yang berbeda-beda menunjukan tidak adanya perbedaan nyata terhadap panjang akar dan jumlah akar bibit yang ditanam pada media tanpa pupuk kandang, hal ini kemungkinan disebabkan sistem perakaran belum berkembang sempurna. Kondisi ini akan berpengaruh terhadap peningkatan kapasitas penyerapan unsur hara yang disediakan oleh pupuk kandang yang diberikan, sehingga tanaman belum dapat merespon pemberian pupuk kandang dengan dosis yang berbeda yang ditunjukkan oleh tidak berbeda nyatanya tinggi tanaman, panjang daun, dan diameter batang bibit tebu.

Hasil penelitian menunjukkan pemberian pupuk kandang kotoran sapi dapat meningkatkan $\mathrm{pH}$ tanah yang berbeda nyata dibanding tanpa pemberian pupuk kandang (kontrol), meskipun peningkatan $\mathrm{pH}$ ini tidak berbeda nyata antara satu dosis dengan dosis yang lain. Hal ini diduga karena pupuk kandang kotoran sapi mampu untuk merangsang aktivitas biologi tanah dan memperbaiki sifat fisik tanah dan secara spesifik berperan dalam meningkatkan ketersediaan fosfor dan unsur-unsur mikro mengurangi pengaruh buruk dari aluminium. Natsir, Salim dan Haldun (2017) menambahkan fungsi pupuk kandang kotoran sapi yaitu untuk menggemburkan lapisan permukaan tanah, meningkatkan populasi jasad renik, meningkatkan daya serap dan daya simpan air, yang keseluruhan dapat meningkatkan kesuburan tanah.

Peningkatan nilai $\mathrm{pH}$ media tanam dibanding tanpa pemberian pupuk kandang sapi diduga disebabkan karena adanya proses pelepasan ion $\mathrm{OH}^{`}$ serta asam-asam organik yang terdapat dalam pupuk kandang sapi tersebut. Bahan organik pupuk kandang menghasilkan humus dan dapat meningkatkan affinitas ion $\mathrm{OH}^{-}$yang berasal dari gugus karboksil dan senyawa fenol. Ion $\mathrm{OH}^{-}$ini dapat menetralisir ion $\mathrm{H}^{+}$yang berada dalam larutan tanah sehingga konsentrasi ion $\mathrm{H}^{+}$dapat ditukar akan menurun.

Secara umum, hasil penelitian menunjukkan bahwa pertumbuhan bibit tebu asal chip berbeda nyata tidak walaupun ada perbedaan dosis pupuk kandang yang diberikan. Kondisi ini diduga karena beberapa faktor, antara lain ; 1) bibit tebu yang digunakan mengalami stress fisiologis karena ditanam di dataran rendah sehingga belum merespons peningkatan kesuburan media tanam. Bibit tebu yang digunakan adalah bibit tebu yang sudah adaptif lama di dataran tinggi, sedangkan lokasi penelitian berada pada dataran rendah. 2) tanaman induk yang digunakan tidak seragam, baik dari segi umur maupun dari selisih waktu panen dengan waktu penanaman chip, sehingga responnya terhadap pemberian pupuk kandang tidak seragam. 3) pupuk kandang kotoran sapi yang digunakan diduga belum terdekomposisi sempurna sehingga belum bisa menyediakan unsur hara yang cukup untuk diberikan kepada tanaman. 4) tidak adanya pemberian pupuk anorganik sebagai pupuk dasar, sedangkan unsur hara dari sumber pupuk kandang kotoran sapi belum tersedia.

\section{KESIMPULAN}

Berdasarkan hasil penelitian yang telah dilakukan dapat disimpulkan bahwa pemberian pupuk kandang kotoran sapi dengan dosis 130 g per media tanam sampai 170 g per media tanam berpengaruh tidak nyata terhadap jumlah anakan, tinggi tanaman, panjang daun, diameter batang, panjang akar, dan jumlah akar bibit tebu asal bud chip, akan tetapi pemberian pupuk kandang kotoran sapi dapat meningkatkan $\mathrm{pH}$ tanah dan berbeda nyata dengan $\mathrm{pH}$ tanah tanpa pemberian pupuk kandang. 


\section{DAFTAR PUSTAKA}

Amir, N, H. Hawalid, dan I.A. Nurhuda. 2017. Pengaruh Pupuk Kandang Terhadap Pertumbuhan Beberapa Varietas Bibit Tanaman Tebu (Saccharum officinarum L.) Di Polybag. Jurnal Klorofil XII-2.Desember 2017. Diakses Januari 2020

Balitbangtan. 2015. Pembenihan Tebu Bud Chips. http://www.litbang.pertanian.go.id/info-teknologi/2326/. Diakses Januari 2020.

Evanita, E, E. Widaryanto, dan Y.B.S. Heddy. 2014. Pengaruh Pupuk Kandang Sapi Pada Pertumbuhan dan Hasil Tanaman Terong Pada Pola Tanam Tumpang Sari Dengan Rumput Gajah Tanaman Pertama. Jurnal Produksi Tanaman. Vol. 2(7). Diakses Januari 2020.

Gusta, A.R, A. Kusumastuti, dan Y. Parapasan, 2015. Pemanfaatan Kompos Kiambang dan Sabut Kelapa Sawit Sebagai Media Tanam Alternatif Pada Prenursery Kelapa Sawit. Jurnal Penelitian Pertanian Terapan 15(2). 151-155. Diakses Januari 2020

Hartatik, W.,Husnain, dan L.R. Widowati.2015. Peranan Pupuk Organik Dalam Peningkatan Produktivitas Tanah dan Tanaman. Jurnal Sumberdaya Lahan Vol. 9(2). Desember 2015. 107-120. Diakses Januari 2020

Havizah, N dan R. Mukarramah. 2017. Aplikasi Pupuk Kandang Kotoran Sapi Pada Pertumbuhan dan Hasil Tanaman Cabai Rawit Di Lahan Rawa Lebak. Jurnal Ziraa’ah. Vol. 42(1). Diakses Januari 2020

Irianti, S, W. Indrawati, dan A. Kusumastuti, 2017. Respons Bibit Bud Chips Batang Atas, Tengah, dan Bawah Tebu (Saccharum officinarum L.) terhadap Aplikasi Dosis Mulsa Bagasse.Jurnal AIP Volume 5 No.1 Mei 2017: 15-28. Diakses Januari 2020.

Natsir, A.N, Salim dan Haldun. 2017. Pupuk Organik. Kerja sama Deepublish dengan LPPM IAIN Ambon. Diakses Januari 2020

PTPN X, 2015. Awal Mula Perkebunan Tebu Di Nusantara. http://ptpn10.co.id/blog/awal-mula-perkebunan-tebu-dinusantara. Diakses Januari 2020

Purwati, R.D. dan Parnidi. 2016. Pengadaan Benih Tebu Bermutu. Peningkatan Produktivitas Tebu Untuk Mempercepat Swasembada Gula. IAARD Press.Jakarta.Diakses Januari 2020 